to the underlying intrathoracic and abdominal structures is important to avoid such complications. In our case the site of insertion of the drain was outside the "triangle of safety", (ie, lower than recommended). This is a common error most junior physicians make, as previously reported. ${ }^{3}$

Small catheters are well tolerated by patients and have been used effectively in draining simple pleural effusion, with acceptable complications. In situations of complex pleural effusions, hemothorax, empyema, and postthoracic procedures, their role is restricted. Tube thoracostomy by a cardiothoracic surgeon or ultrasound-guided drainage by a radiologist would be safer and achieve the effective result. ${ }^{4}$ In centers in which ultrasonography is available, insertion of a pigtail drain under ultrasonographic guidance is recommended, especially for complex effusions.

In our case the complication could have been prevented if there had been adherence to the British Thoracic Society guidelines for intercostal drain insertion. Also, the stylet and puncture needle of the Bonanno catheter is very long. Depth perception and needle control can be an issue while inserting them in the pleural cavity, for which they are not designed. We recommended changes to the design of such catheters to make them more user-friendly and reduce complications during insertion. ${ }^{5}$

To our knowledge, a drain piercing the left ventricle and lying in the left ventricular outflow tract with its tip in the aortic root has not been reported in the literature. Fortunately, early recognition of the misplaced drain and timely management led to the uneventful recovery of the patient. Strict adherence to the principles of drain insertion, ultrasound-guided insertion of pigtail catheters, or both can reduce the risks of complications.

\section{References}

1. Laws D, Neville E, Duffy J; Pleural Diseases Group, Standards of Care Committee, British Thoracic Society. BTS guidelines for the insertion of a chest drain. Thorax. 2003;58(suppl 2):53-9.

2. Abad C, Padron A. Accidental perforation of the left ventricle with a chest drain tube. Tex Heart Inst J. 2002;29:143.

3. Griffiths JR, Roberts N. Do junior doctors know where to insert chest drains safely? Postgrad Med J. 2005;81:456-8.

4. Cantin L, Chartrand-Lefebvre C, Lepanto L, Gianfelice D, Rabbat A, Aubin B, et al. Chest tube drainage under radiological guidance for pleural effusion and pneumothorax in a tertiary care university teaching hospital: review of 51 cases. Can Respir J. 2005;12:29-33.

5. Asopa S, Patel A. Bonnano's catheter: a less invasive and cost-effective alternative for drainage of pleural effusion. J Thorac Cardiovasc Surg. 2006;132:1503-4.

\title{
Give the patient another chance: Peratrial device closure of a secundum atrial septal defect that failed percutaneous device closure
}

Kai-yu Tao, MS, ${ }^{\text {a }}$ Qi An, MS, ${ }^{a}$ Chang-ping Gan, MS, ${ }^{a}$ Hong Tang, MD,${ }^{b}$ Yuan Feng, MD, ${ }^{\mathrm{c}}$ and Hai-bo Song, MD,${ }^{\mathrm{d}}$ Chengdu, China

Percutaneous device closure of a secundum atrial septal defect (ASD) is an effective and fairly safe alternative to surgical intervention, but it is technically challenging and is not always performed smoothly in patients with large ASDs. ${ }^{1,2}$ We report a deft recovery of a dislocated ASD occluder in the right atrium without cardiopulmonary bypass (CPB) through an incision on the right atrial wall with inferior

\footnotetext{
From the Departments of Thoracic and Cardiovascular Surgery, ${ }^{\mathrm{a}}$ Echocardiography, Cardiology, ${ }^{\mathrm{c}}$ and Anesthesiology, ${ }^{\mathrm{d}}$ West China Hospital, Sichuan University, Chengdu, China.

Received for publication Jan 11, 2008; revisions received Feb 15, 2008; accepted for publication March 23, 2008.

Address for reprints: Qi An, MS, Department of Thoracic and Cardiovascular Surgery, West China Hospital, Sichuan University, Chengdu, Sichuan 610041, China (E-mail: anqi8890@163.com).

J Thorac Cardiovasc Surg 2009; 137:1024-7

$0022-5223 / \$ 36.00$

Copyright (c) 2009 by The American Association for Thoracic Surgery doi:10.1016/j.jtcvs.2008.03.030
}

partial median sternotomy, after which a peratrial device closure of the ASD was successfully performed.

\section{CLINICAL SUMMARY}

A 33-year-old woman with a large secundum ASD of 32 $\times 28 \times 27 \mathrm{~mm}$ in size with a $13-\mathrm{mm}$ superior rim, a $12-\mathrm{mm}$ inferior rim, and an insufficient anterior rim was referred to our hospital. A percutaneous device closure was performed under fluoroscopic guidance in a catheterization laboratory, but the 34-mm occluder was dislocated into the right atrium after its release from the cable, and attempts to recover the occluder were failed. Considering the risk of blocking the tricuspid (Figure 1, A), an emergency operation was required. In the operating room the right atrium was exposed with an inferior partial median sternotomy. Meanwhile, one finger of the glove was cut down to make a finger cot, which was put on the surgeon's index finger outside the glove, and then concealed a small hook between the finger 

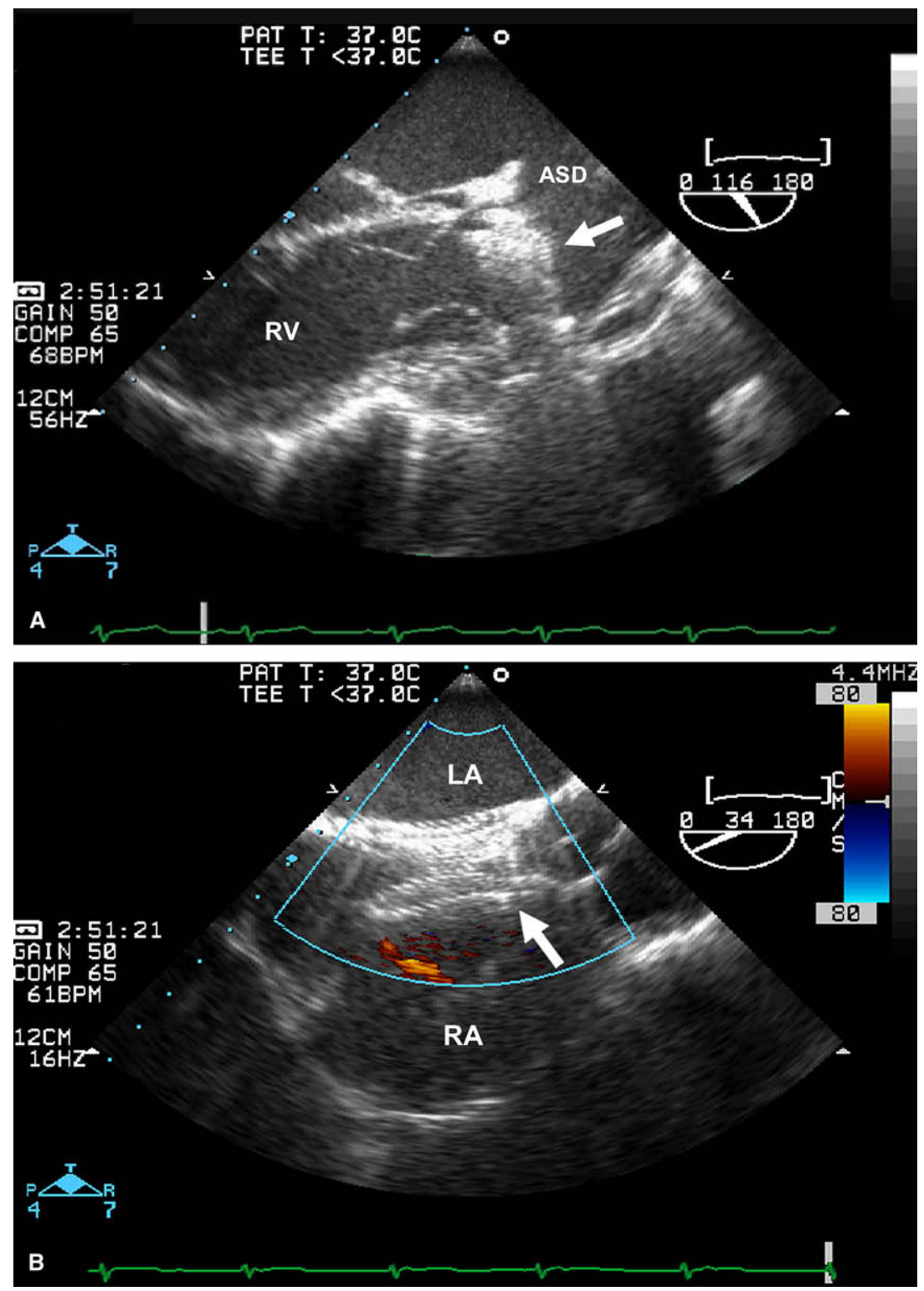

FIGURE 1. Transesophageal echocardiography. A, The dislocated atrial septal defect ( $A S D$ ) occluder (arrow) was in the right atrium near the tricuspid valve. $R V$, Right ventricle. B, The ASD was closed with an ASD occluder (arrow), and no residual shunt was found. $L A$, Left atrium; $R A$, right atrium.

cot and the glove to avoid scratching the cardiac muscle (Figure 2). Then a purse-string suture was placed on the right auricular appendix. The index finger with a finger cot then was inserted into the right atrium through the purse-string suture, the hook was protruded to capture the dislocated occluder when the index finger touched it, and the right atrial free wall with the occluder was clamped with a lateral wall clamp. Another purse-string suture was placed on the clamped atrial wall in which an incision was made, the occluder was taken out through the incision, and the purse-string suture was tightened up. Then a peratrial device closure was performed under the guidance of transesophageal echocardiography (Philips, Eindhoven, The Nether- lands) as reported by Hongxin and colleagues. ${ }^{3}$ An ASD occluder of the same size $(34 \mathrm{~mm})$ was used in the procedure, considering the anatomic features, and the occluder was released after confirmation of its position and stabilization. A recheck echocardiogram revealed that the occluder was in perfect position, and no residual shunt was found (Figure 1,B). The patient was discharged on day 7 after the operation, and the position of the occluder was confirmed at 3-month follow-up.

\section{DISCUSSION}

Percutaneous device closure of ASDs is not free of potential complications or failure of implantation, especially when 

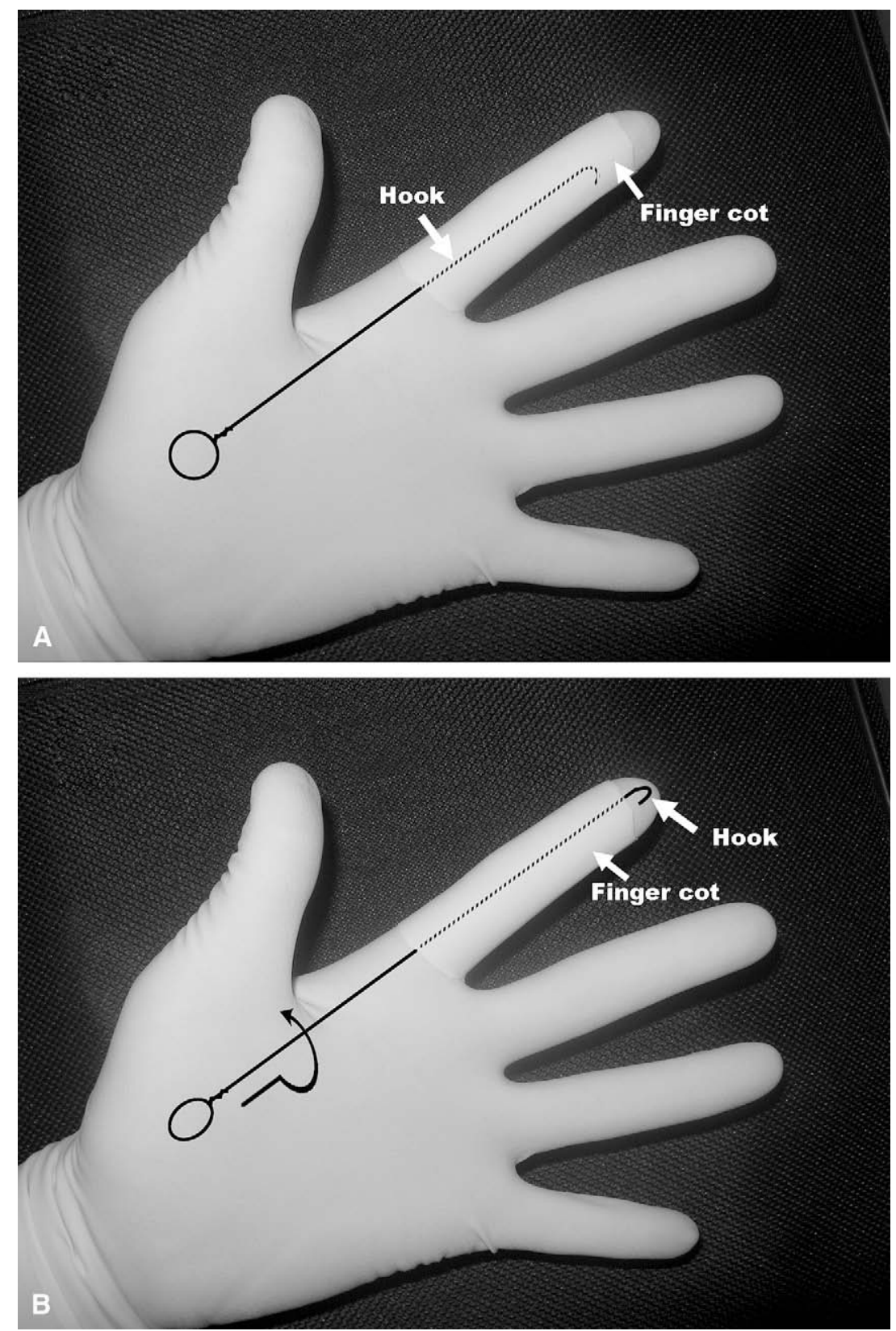

FIGURE 2. The capture set-up, including a finger cot and a hook. A, A small hook was concealed between the finger cot and the glove to avoid scratching the endocardial structure. B, The hook was protruded to capture the dislocated occluder.

closing a large ASD. ${ }^{2,4}$ Studies reported that $27.8 \%$ of those failures were due to systemic or pulmonary vein anomalies, and the instability of the device or the large diameter of the ASD $(25 \pm 6 \mathrm{~mm})$ accounts for $44.4 \%$ to $80 \%$ of the failures. ${ }^{1,4}$ In the percutaneous closure procedure, it was not technically easy to implant the left atrial disk in the right position in patients with a large-diameter $\mathrm{ASD}^{2}$ but it was relatively easy in Peratrial device closure because the proper location for the atrial puncture can be successively achieved with transesophageal echocardiographic guidance. Thus patients in whom the percutaneous device closure has failed might still be promising candidates for Peratrial device closure.

To give the patient another chance to survive without the risk of inflammatory response caused by CPB, we decided to capture the dislocated occluder with the heart beating. The capture procedure and peratrial device closure have some advantages in causing less complications compared with the pericardial effusions, long incision scar, and inflammatory response of conventional operations and $\mathrm{CPB} .{ }^{5}$ First there is less trauma, the length of the incision is equivalent to half the length of the sternum, the scar will be covered 
by décolletage, and it will not leave the cosmetic problem for a lady who cares about her physical appearance. More importantly, the procedures are executed off-pump. The second benefit is safety: capture of the dislocated occluder through the inferior partial median sternotomy is relatively easier than other approaches for perfect exposure. When the capture or the closure procedure is failed for some reason, the incision can be extended upward, and conventional surgical closure can be performed immediately.

To our knowledge, this is the first case in which a dislocated occluder has been captured without CPB and in which the peratrial device closure was performed after the failure of percutaneous occluder implantation. The case reminds us that capture of a dislocated occluder without $\mathrm{CPB}$ is technically feasible and that peratrial device closure might be a new direction for therapy of septal defects.

\section{References}

1. Fischer G, Stieh J, Uebing A, Hoffmann U, Morf G, Kramer HH. Experience with transcatheter closure of secundum atrial septal defects using the Amplatzer septal occluder: a single centre study in 236 consecutive patients. Heart. 2003;89: 199-204.

2. Fu Y-C, Cao Q-L, Hijazi ZM. Device closure of large atrial septal defects: technical considerations. J Cardiovasc Med (Hagerstown). 2007;8:30-3.

3. Hongxin L, Wenbin G, Lijun S, Zhengjun W, Hao L, Chengwei Z, et al. Intraoperative device closure of secundum atrial septal defect with a right anterior minithoracotomy in 100 patients. J Thorac Cardiovasc Surg. 2007;134:946-51.

4. Berdat PA, Chatterjee T, Pfammatter JP, Windecker S, Meier B, Carrel T. Surgical management of complications after transcatheter closure of an atrial septal defect or patent foramen ovale. J Thorac Cardiovasc Surg. 2000;120:1034-9.

5. Thomson JDR, Aburawi EH, Watterson KG, Van Doorn C, Gibbs JL. Surgica and transcatheter (Amplatzer) closure of atrial septal defects: a prospective comparison of results and cost. Heart. 2002;87:466-9.

\title{
Stent graft coarctation after frozen elephant trunk procedure: An unusual complication
}

\author{
Davide Pacini, MD, ${ }^{\mathrm{a}}$ Alessandro Armaro, MD, ${ }^{\mathrm{a}}$ Luca Di Marco, MD, ${ }^{\mathrm{a}}$ Vincenzo Russo, MD, ${ }^{\mathrm{b}}$ and Roberto Di Bartolomeo, MD, \\ Bologna, Italy
}

\section{Supplemental material is available online.}

Recently, a hybrid repair combining endovascular treatment with conventional surgery, known as the "frozen elephant trunk" technique, ${ }^{1}$ has been described as a single-stage procedure for the treatment of diffuse pathology of the thoracic aorta. We report an interesting case of a patient with Marfan syndrome who underwent frozen elephant trunk repair in which coarctation of the endoprosthesis was postoperatively diagnosed and successfully treated with another endovascular procedure.

\section{CLINICAL SUMMARY}

A 52-year-old male patient with Marfan syndrome and severe scoliosis leading to severe respiratory insufficiency

\footnotetext{
From the Departments of Cardiac Surgery and Radiology, ${ }^{\mathrm{b}}$ S Orsola-Malpighi Hospital, University of Bologna, Bologna, Italy.

Received for publication Jan 24, 2008; accepted for publication March 22, 2008.

Address for reprints: Davide Pacini, MD, Unità Operativa di Cardiochirurgia, Università degli studi di Bologna, Policlinico S Orsola, Via Massarenti, 9, 40138 Bologna, Italia (E-mail: dpacini@hotmail.com).

J Thorac Cardiovasc Surg 2009;137:1027-9

$0022-5223 / \$ 36.00$

Copyright $(c) 2009$ by The American Association for Thoracic Surgery

doi:10.1016/j.jtcvs.2008.03.036
}

(Figure 1, A) and previous mitral valve replacement had an acute type B aortic dissection that was medically treated. Six months later, the patient was referred to our department because of rapid dilatation of the false lumen of the descending thoracic aorta, which presented a severe tortuosity, facing the spinal column scoliosis (Figure 1, $B$ and Figure E1, Al-A4). The ascending aorta and the aortic root were dilated, and moderate aortic valve regurgitation was demonstrated. The patient underwent aortic root replacement with a composite valve graft together with aortic arch and descending aorta replacement in a frozen elephant trunk procedure. Cardiopulmonary bypass was established through the right axillary artery and the right atrium. The cerebral protection method consisted of antegrade selective cerebral perfusion and mild hypothermia. ${ }^{2}$ Myocardial protection was achieved with cold crystalloid cardioplegia. The stent graft system (E-vita open; Jotec Inc, Hechingen, Germany) was introduced in an antegrade manner in the true lumen of the descending aorta over a stiff guide wire previously positioned under transesophageal echocardiographic control, through the right femoral artery. The proximal landing zone was approximately $4 \mathrm{~cm}$ distal to the left subclavian artery.

Weaning from cardiopulmonary bypass was uneventful, as was the initial postoperative course. A computed tomographic scan on postoperative day 9 revealed severe kinking 